\title{
Water-In-Oil Emulsions through Porous Media and the Effect of Surfactants: Theoretical Approaches
}

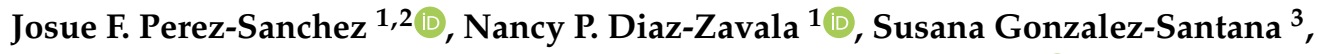 \\ Elena F. Izquierdo-Kulich ${ }^{3}$ and Edgardo J. Suarez-Dominguez ${ }^{2, * \mathbb{D}}$ \\ 1 Centro de Investigación en Petroquímica, Instituto Tecnológico de Ciudad Madero-Tecnológico Nacional de \\ México, Altamira, Tamaulipas 89600, Mexico; jfperez@live.com.mx (J.P.-S.); npatdiaz@hotmail.com (N.D.-Z.) \\ 2 Facultad de Arquitectura, Diseño y Urbanismo, Universidad Autónoma de Tamaulipas, Tampico, \\ Tamaulipas 89000, Mexico \\ 3 Departamento de Química-Física, Facultad de Química, Universidad de la Habana, La Habana 10400, Cuba; \\ ejsuarezd@gmail.com (S.G.-S.); elenaik@fq.uh.cu (E.I.-K.) \\ * Correspondence: edgardo.suarez@uat.edu.mx; Tel.: +528332412000 (ext. 3586)
}

Received: 14 August 2019; Accepted: 9 September 2019; Published: 12 September 2019

check for updates

\begin{abstract}
The most complex components in heavy crude oils tend to form aggregates that constitute the dispersed phase in these fluids, showing the high viscosity values that characterize them. Water-in-oil (W/O) emulsions are affected by the presence and concentration of this phase in crude oil. In this paper, a theoretical study based on computational chemistry was carried out to determine the molecular interaction energies between paraffin-asphaltenes-water and four surfactant molecules to predict their effect in $\mathrm{W} / \mathrm{O}$ emulsions and the theoretical influence on the pressure drop behavior for fluids that move through porous media. The mathematical model determined a typical behavior of the fluid when the parameters of the system are changed (pore size, particle size, dispersed phase fraction in the fluid, and stratified fluid) and the viscosity model determined that two of the surfactant molecules are suitable for applications in the destabilization of W/O emulsions. Therefore, an experimental study must be set to determine the feasibility of the methodology and mathematical model displayed in this work.
\end{abstract}

Keywords: $\mathrm{MMH}$ in asphaltenes; emulsions in porous media; pressure drop; surfactant activity

\section{Introduction}

Asphaltenes are part of the heaviest fraction of crude oils, and due to their high chemical structure complexity with active sites that promote strong intermolecular interactions (such as $\pi-\pi$ stacking, hydrogen bonding, van der Waals interactions, among others), they tend to form aggregates that become a dispersed phase which increases the viscosity of the oil [1-3]. If these aggregates reach a critical size, they could form a deposition of precipitates in the walls of tubes, making crude oil transportation difficult and poorly efficient [4].

Viscosity reduction has been studied under the effect of chemicals such as surfactants or flow enhancers. Nevertheless, the molecular mechanism of action through which viscosity decreases is not clear [5-7]. Also, it has been observed that the action of these chemicals also affects the stabilization of water-in-oil $(\mathrm{W} / \mathrm{O})$ and oil-in-water $(\mathrm{O} / \mathrm{W})$ emulsions $[6,8]$. It has been hypothesized that the enhancer interacts with the heaviest components and reduces the dispersed phase and viscosity as a consequence, even at relatively low concentrations of the enhancer which is one of the desirable properties of these type of products; therefore, the emulsion formation related to the water content and the water-asphaltene interaction has become a topic of interest [1,9]. 
In the petroleum industry, heavy crude oils are often produced from reservoirs in the form of W/O or $\mathrm{O} / \mathrm{W}$ emulsions, and they are transported in reservoir rocks with a wide range of permeabilities. Several models have been reported in the literature to describe flow mechanisms of emulsions through porous media [10,11].

This work aimed to establish a theoretical model to describe the flow of W/O emulsions through porous media and determine the influence of four surfactant molecule models on emulsion stability and the final effect on pressure drop. The molecular interactions were studied under the Multiple Minimum Hypersurfaces (MMH) method, from which the association energies are determined to show the most probable associations that occur in the system formed by molecules of asphaltenes, paraffin, water, and surfactant.

\subsection{Mathematical Analysis of the Emulsion Flow through Porous Beds}

In this work, the linking of emulsion properties with the equations to estimate the pressure gradient through porous beds $(\Phi)$, involves the Carmen-Kozeny and Burke-Plumber equations in conjunction with the analysis presented by Cheng et al. [12]. Considering a solid tube with diameter $D$ and length $L$, the following expressions are obtained:

For the laminar regime:

$$
\begin{gathered}
R_{e, p}=V d_{p}\left(\frac{2\left(\mu_{d}+\mu_{m}\right)}{\mu_{m}}\right)\left(\frac{\rho_{m}(1-\phi)+\rho_{d} \phi}{2\left(\mu_{d}+\mu_{m}(1+\phi)\right)+5 \phi \mu_{d}}\right) \\
\Phi=75 V \mu_{m} \frac{(\varepsilon-1)^{2}}{\varepsilon^{3} d_{p}^{2}}\left(1+\left(\frac{\mu_{m}+\frac{5}{2} \mu_{d}}{\mu_{m}+\mu_{d}}\right) \phi\right) ; R_{e, p} \leq 10
\end{gathered}
$$

For the transition regime:

$$
\begin{gathered}
\Phi=\frac{75 V \mu_{m}(\varepsilon-1)^{2}}{\varepsilon^{3} d_{p}^{2}}\left(1+\left(\frac{\mu_{m}+\frac{5}{2} \mu_{d}}{\mu_{m}+\mu_{d}}\right) \phi\right)+\frac{1.75(1-\varepsilon) V^{2}}{\varepsilon^{3}} \frac{\rho_{m}(1-\phi)+\rho_{d} \phi}{2 d_{p}^{2}} \\
10<R_{e, p}<10^{3}
\end{gathered}
$$

For the turbulent system:

$$
\Phi=1.75 \frac{(1-\varepsilon)}{\varepsilon^{3}} \frac{\rho_{m}(1-\phi)+\rho_{d} \phi}{2 d_{p}^{2}} V^{2} ; 10^{3} \leq R_{e, p}
$$

where $\rho_{m}$ and $\mu_{m}$ are the density and viscosity of dispersion media, $\rho_{d}$ and $\mu_{d}$ are the density and viscosity of the dispersed phase; respectively, $V$ is the total volume, $d_{p}$ is the particle diameter, $\phi$ is the dispersed phase volume fraction, and $\varepsilon$ represents the porosity.

\subsection{Effect of Emulsion Destruction on the Pressure Gradient}

The demulsifying action produced by surfactant addition in low concentrations to the crude oil with water content destroys the dispersed system producing phase separation. In such a way, it can be considered that some of the solid particles are in contact with the crude oil, and some are in contact with the water. Since the water is significantly less viscous than oil, this should bring an apparent decrease in the cutting tension that manifests itself as a reduction in the pressure gradient.

From this behavior, it will be considered that phase separation is established in a stratified manner and that the flow regime is laminar (a turbulent regime induces the dispersion of one phase in another). The porous bed is visualized as channels in such a way that the empirical equations above can be employed. Also, the viscosity considered in the model is the global viscosity obtained for stratified 
flow in a system of parallel plates, where the position of the interface is related to the composition of the flow according to the equation:

$$
v_{1}=\frac{\left(\lambda^{2}-\lambda\right) \alpha^{4}-2 \lambda \alpha^{3}+3 \lambda \alpha^{2}}{\left(\lambda^{2}-2 \lambda+1\right) \alpha^{4}+(4 \lambda-4) \alpha^{3}+(6-6 \lambda) \alpha^{2}+(4 \lambda-4) \alpha+1}
$$

and the global viscosity is determined as [13]:

$$
\mu_{1+2}=\mu_{2} \frac{\alpha(\lambda-1)+1}{\alpha(4 \lambda-4)+\alpha^{4}\left(\lambda^{2}-2 \lambda+1\right)+\alpha^{3}(4 \lambda-4)-\alpha^{2}(6 \lambda-6)+1}
$$

where the subscripts 1 and 2 represent each of the fluids and

$$
\lambda=\frac{\mu_{2}}{\mu_{1}}
$$

\subsection{Influence of the Surfactant on Global Viscosity}

Viscosity is a transport property that depends on the concentration and molecular structure of the compounds, the molecular interactions between them, and the pressure/temperature conditions of the system [14]. In the case of gases, the kinetic theory has been useful to predict the viscosity behavior as a function of the thermodynamic properties; however, for liquids, it is difficult to manage the effect of the molecular interactions whose influence is more significant due to the vibrations of the molecules in the spatial field created by the neighboring molecules [15].

Fluid movement is only possible when molecules go over the activation energy $\Delta G_{0}(\mathrm{~J} / \mathrm{mol})$, which depends on the molecular interactions in the system. From this basic statement, Eyring [16] proposed a relationship between viscosity and temperature for non-Newtonian liquids:

$$
\mu=\frac{N h}{V} \exp \left(-\frac{\Delta \mathrm{G}_{0}}{\mathrm{~T}}\right)
$$

where $N$ is the Avogadro number, $h$ is the Plank constant, and $V$ is the molar volume which can be assumed to be constant in a given temperature range.

The physico-chemical mechanism associated with the viscosity reduction of crude oil emulsions is not fully understood. For some surfactants, the experimental data shows that these kinds of chemicals increment the stability of the asphaltene dispersed phase in such a way that reduces the asphaltene fraction in the form of aggregates [17]. On the other hand, a suitable surfactant can lead to the destabilization of the dispersed phase formed by water, which results in a complete phase separation and the origin of a biphasic fluid that promotes a significant reduction in frictional pressure drop losses in the system.

Therefore, the molecular interaction energies that produce stabilization/destabilization of the dispersed phase can be considered proportional to the activation energy, and therefore, determining such interactions is fundamental in the study of fluid behavior.

\section{Materials and Methods}

\section{Study of Molecular Interactions Using the MMH Methodology}

The Multiple Minimum Hypersurfaces (MMH) approach allows us to study the collective effects of the molecular environment by combining the quantum and mechanical procedures for the calculation of the molecular aggregate energies with statistical thermodynamics for the determination of the thermodynamic properties of association of polyatomic systems [18]. This methodology explores the potential energy surface to find the molecular arrangements, with their respective geometries and 
energies, that group the most important significant states for the calculation of the thermodynamic properties of the complete system [19].

In the MMH procedure, a set of random ordering of the different molecules under study is generated and rearranged until the minimum value of the internal energy is obtained. These minima are considered as a canonical representative set of the macroscopic state (closed system at constant temperature and pressure) according to a typical Boltzmann distribution. Through this methodology, a random conformational search is performed, from which the essential conformations that can be established between the molecules forming the aggregate under study are analyzed. The subsequent optimization of the cells is performed by mechano-quantum calculation methods, for which a semi-empirical Hamiltonian is used.

The reference state for the calculations is assumed to be a set of the same number of non-interacting molecules, which implies a process of isothermal association from a molecular point of view. Degrees of freedom (translational, vibrational and rotational) are considered identical in the individual molecules, and the molecular aggregates for each cell are of the same type as the molecular aggregate created, so the sum of their total energies serves as the reference value in the massive scale. Consequently, the energy of the cell concerning the new reference scale $\Delta \varepsilon_{i}$, is:

$$
\Delta \varepsilon_{i}=\varepsilon_{i}-\varepsilon_{r e f}
$$

where:

$$
\varepsilon_{r e f}=\sum_{i} \varepsilon_{i}
$$

In statistical terms, and setting the non-associated molecules as a reference, the following equations are used to analyze the association energies in the system:

$$
\begin{gathered}
U=\sum q_{i} \text { Easoc }_{i} \\
\text { Sasoc }=-k \sum q_{i} \ln \left(q_{i}\right) \\
\text { Aasoc }=-k R T \ln \left(q_{i}\right)
\end{gathered}
$$

where $U, E a s o c, S a s o c$, and Aasoc are the internal energy, the association energy, entropy, and Helmholtz free energy; respectively, $k$ is an integration constant, $T$ is temperature and $R$ is the gas constant. $q$ is the molecular partition function that represents the sum of the corresponding states extended to the total system states and is represented by:

$$
q_{j}=\frac{e^{\left(-\beta E_{j}\right)}}{\sum e^{\left(-\beta E_{j}\right)}}, \beta=\frac{1}{T K}
$$

The analyzed cases in this study correspond to the molecular associations of four different surfactant molecules and the paraffin and asphaltene content in crude oil. For each of the molecular associations, the most favorable conformations were considered through the application of the GAUSSIAN09 software with the B3LYP method. A statistical analysis of the results was performed to determine the optimal conformation (minimum energy) which was optimized using the program MOPAC2016. Figure 1 shows the molecular models for paraffin and asphaltene single molecules, and the surfactant used in the interaction study. 


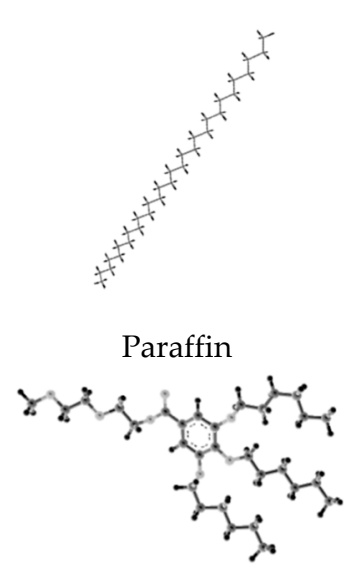

Molecule B

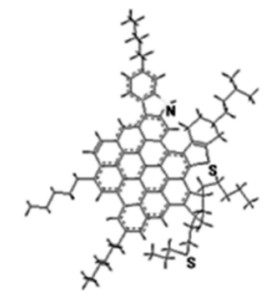

Asphaltene

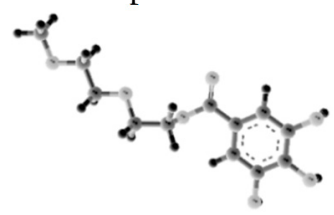

Molecule C

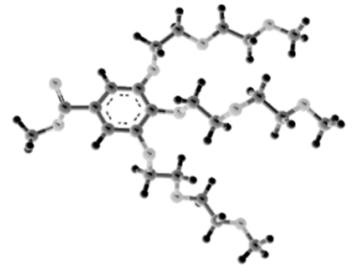

Molecule A

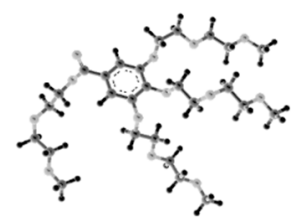

Molecule D

Figure 1. Initial structures considered.

The models in Figure 1 for paraffin and asphaltene were taken as reference from previous work presented by Suarez et al. in which the interaction with asphaltene from Mexican crude oil was studied under the effect of a viscosity bio-reducer [13,20,21]. Molecules A, B, C, and D in Figure 1 are gallic acid ethoxylated derivatives designed to have different polarities by adding tri-ethoxylated chains as ether/ester derivatives, and are the next novel materials: $\mathrm{A}=$ gallic acid with three ethoxylated chains (ether), B = gallic acid with one ethoxylated chain (ester) and three hexyl chains, $\mathrm{C}=$ gallic acid with one ethoxylated chain (ester), and D = gallic acid with four ethoxylated chains (ester/ether). This work arises as a preliminary analysis to determine the effect of the model proposed on emulsion properties. The associations studied by MMH methodology were as follows, where $\alpha=$ molecule A, B, C or D:

- $\alpha$-Asphaltene

- $\alpha$-Paraffin

- $\alpha-3 \mathrm{H}_{2} \mathrm{O}$

- $\alpha$-Asphaltene-Paraffin

- $\alpha$-Asphaltene-Paraffin- $3 \mathrm{H}_{2} \mathrm{O}$

\section{Results: Theoretical Predictions}

The results from the MMH analysis are shown in Table 1. According to the results, for an ideal crude oil with paraffin and asphaltenes in a water-free system whose structures match the models used for the calculations, molecule $C$ is more effective to reduce viscosity. In the presence of water, the viscosity is even lower; therefore, model $C$ is the most effective to act as surfactant. Similar behavior is expected for molecule B. If water is significantly less viscous than the paraffin-asphaltene mixture, the predicted results fit the expected due to experimental observations that show that the addition of a lower viscosity component results in a viscosity reduction of the mixture [22]. Figures 2 and 3 show the optimal conformations that represent the results in Table 1. 
Table 1. Values of the molecular interaction energies determined using the Multiple Minimum Hypersurfaces (MMH) methodology.

\begin{tabular}{ccc}
\hline Interaction & Energy (eV) in a Water-Free System & Energy (eV) with $\mathbf{3 H}_{\mathbf{2}} \mathbf{O}$ \\
\hline Total internal energy values obtained for optimal conformation cell (minima) \\
\hline Asphaltene-Paraffin-Molecule A & $-23,496.4$ & $-24,464.6$ \\
Asphaltene-Paraffin-Molecule B & $-23,367.3$ & $-24,335.3$ \\
Asphaltene-Paraffin-Molecule C & $-20,669.3$ & $-21,637.4$ \\
Asphaltene-Paraffin-Molecule D & $-24,685.4$ & $-25,653.5$ \\
\hline & Internal energy (Easoc) & \\
\hline Asphaltene-Paraffin-Molecule A & -202.6 & -108.2 \\
Asphaltene-Paraffin-Molecule B & -136.8 & -75.9 \\
Asphaltene-Paraffin-Molecule C & -146.1 & -76.2 \\
Asphaltene-Paraffin-Molecule D & -181.4 & -98.9 \\
\hline & Entropy (Sasoc) & 12.7 \\
\hline Asphaltene-Paraffin-Molecule A & 7.6 & 19.7 \\
Asphaltene-Paraffin-Molecule B & 9.5 & 26.1 \\
Asphaltene-Paraffin-Molecule C & 14.6 & 17.0 \\
Asphaltene-Paraffin-Molecule D & 12.7 & \\
\hline & Helmholtz free energy (Aasoc) & -112.0 \\
\hline Asphaltene-Paraffin-Molecule A & -204.8 & -81.8 \\
Asphaltene-Paraffin-Molecule B & -139.7 & -84.0 \\
Asphaltene-Paraffin-Molecule C & -150.5 & -103.9 \\
Asphaltene-Paraffin-Molecule D & -185.2 & \\
\hline
\end{tabular}

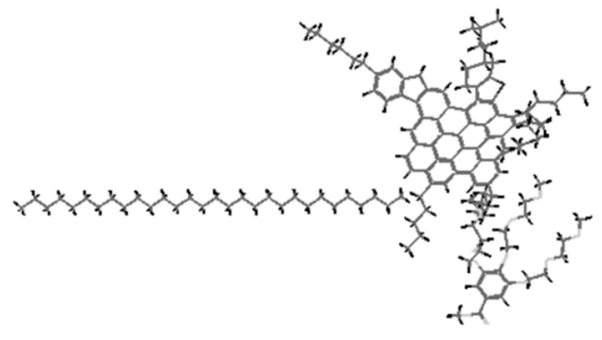

Asphaltene-Paraffin-Molecule A

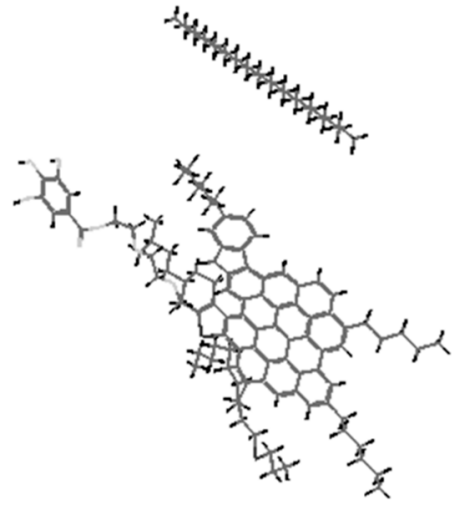

Asphaltene-Paraffin-Molecule C

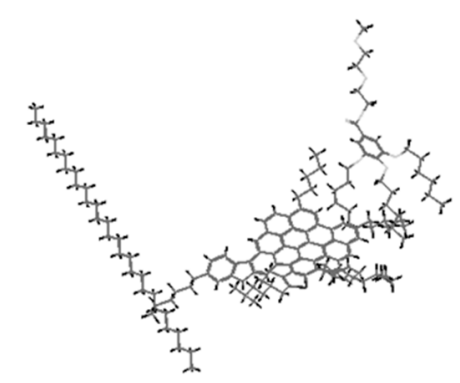

Asphaltene-Paraffin-Molecule B

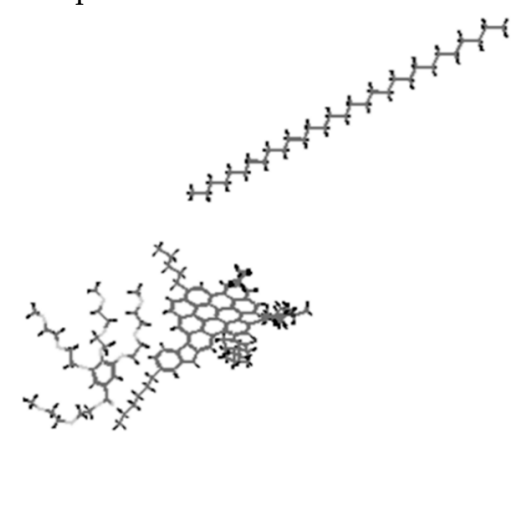

Asphaltene-Paraffin-Molecule D

Figure 2. Free-water conglomerate interactions. 


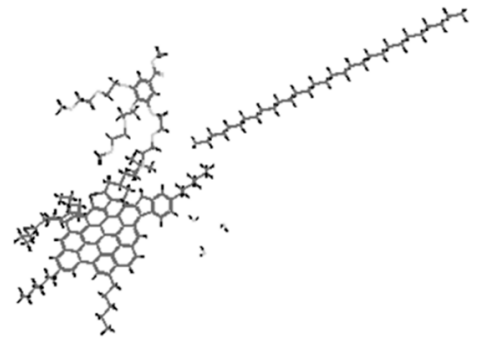

Asphaltene-Paraffin-Molecule A

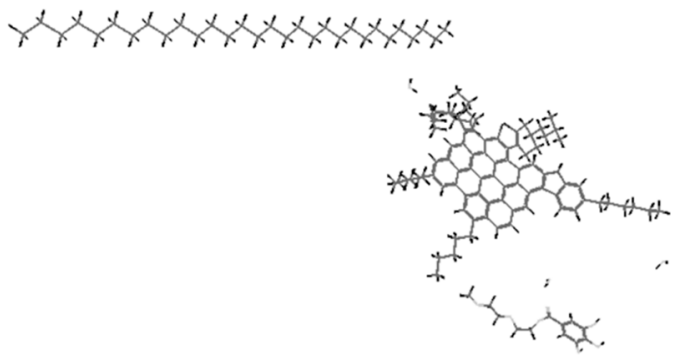

Asphaltene-Paraffin-Molecule C

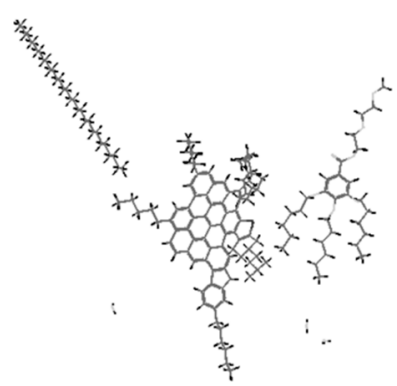

Asphaltene-Paraffin-Molecule B

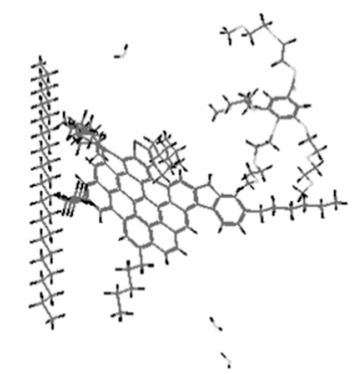

Asphaltene-Paraffin-Molecule D

Figure 3. Interaction of conglomerates and three water molecules.

For the considerations established previously (Equation (9)), the activation energy related to fluid movement is proportional to the internal energy obtained through MMH methodology. Figure 4 shows the predicted qualitative behaviors of viscosity for the molecular interactions studied.

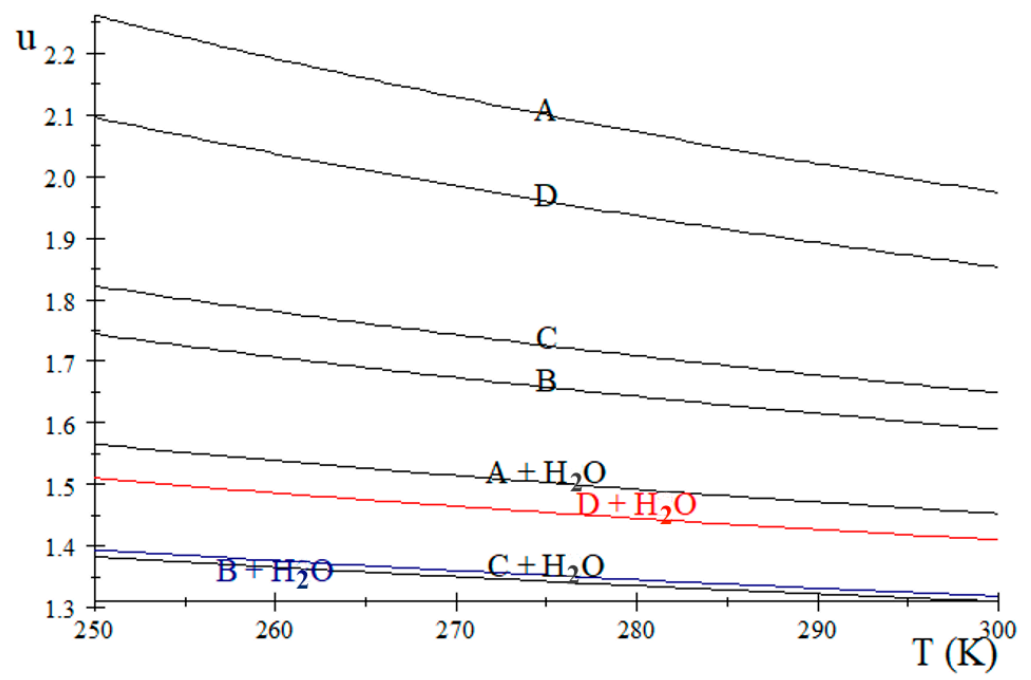

Figure 4. Qualitative behavior of viscosity for the paraffin-asphaltene-surfactant mixture predicted by the Eyring equation. $u$ is the relationship between the predicted viscosity and a viscosity reference value at a given temperature $(u=\mu / \mu$ at $298,15 \mathrm{~K})$.

These results are only valid if there is a complete mixture of the system. However, in real systems, water and asphaltene molecules confer colloidal properties to crude oil that result in an additional increment of viscosity. Water and asphaltenes are polar molecules that, when immersed in a non-polar media (paraffin), tend to form aggregates. This behavior eventually evolves into the formation of a dispersed phase. Such dispersed particles distort the flow pattern which manifests in higher viscosity, and finally, the fluid exhibits a non-Newtonian behavior (at low temperatures) [23,24]. If experimental data demonstrate that a surfactant molecule reduces viscosity, then it can be employed as a flow enhancer in extraction and transport processes in the crude oil industry. 
In order to analyze the predictions of the mathematical analysis developed in Sections 1.1 and 1.2, we will consider a crude oil with a certain water content in such a way that it is considered a W/O emulsion, and the physical properties of both fluids are shown in Table 2. The crude oil properties data were obtained from the characterization of Mexican crude oils and are presented as average values for wells in northern Mexico [25-27].

Table 2. Properties of the emulsion components.

\begin{tabular}{ccc}
\hline Phase & Density $\left(\mathbf{k g} / \mathbf{m}^{3}\right)$ & Viscosity $(\mathbf{P a} \cdot \mathbf{s})$ \\
\hline Crude oil (dispersion medium) & 980 & 8 \\
\hline Water (dispersed phase) & 1000 & 0.001 \\
\hline
\end{tabular}

The objective is to predict the influence of water content on the mixture and the characteristics of pore-filling on the behavior of the pressure gradient for the velocity of the fluid. In this sense, the attributes of the porous media considered are the porosity and the average particle size.

Figure 5 shows the effect of the volume fraction of the dispersed phase $(\phi)$ on the behavior of the pressure gradient concerning the average velocity for a porosity $\varepsilon=0.4$, where the pressure gradient increases with the volume fraction of the dispersed phase. This result is expected as the emulsion viscosity increases with the concentration of the dispersed phase [28]. On the other hand, the pressure gradient is extremely high, because it has been considered as a bed filled with sand particles of average diameter equal to $1 \mathrm{~mm}$. Hence, the surface area of the solid in which the fluid is in contact with is very high, with a consequent increase in the cut tension on the surface of the particles.

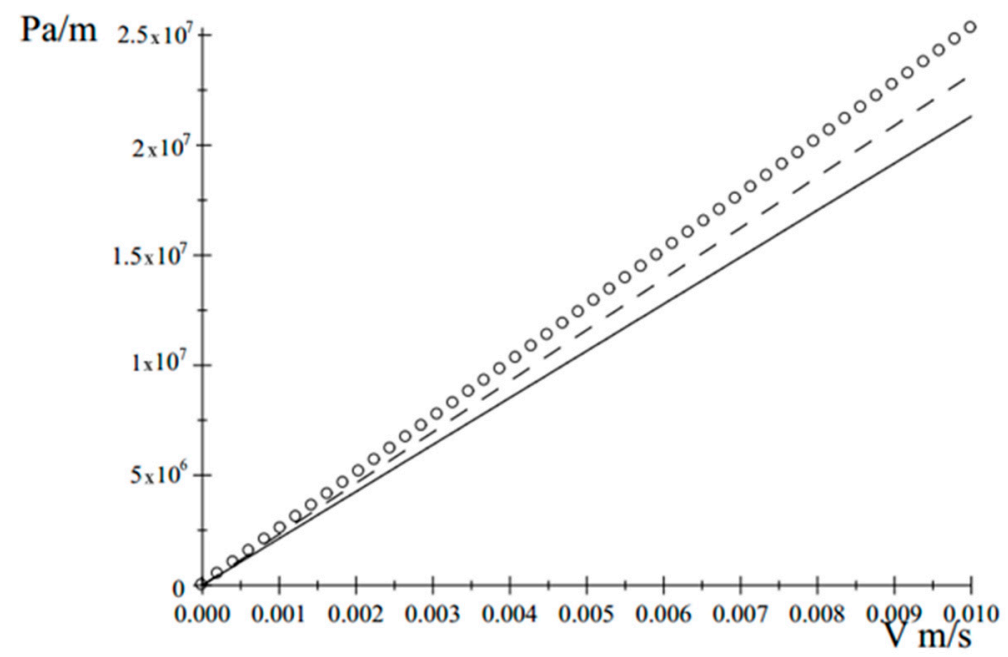

Figure 5. Emulsion composition effect with porosity $\varepsilon=0.4$, particle diameter $d_{p}=0.001 \mathrm{~m}$, and dispersed phase volume fraction $\phi=0.01$ (solid line), 0.1 (dashed line), and 0.2 (dotted line).

Figure 6 shows the effect of the particle size where now the bed has been considered to stone-filled with the stones having an average diameter of $1 \mathrm{~cm}, 2 \mathrm{~cm}$, and $3 \mathrm{~cm}$. It is observed that, at the same fluid velocity profile, the pressure gradient decreases considerably when the particle size increases, with a consequent decrease of both the surface area of the solid and the cutting tension on the surface. 


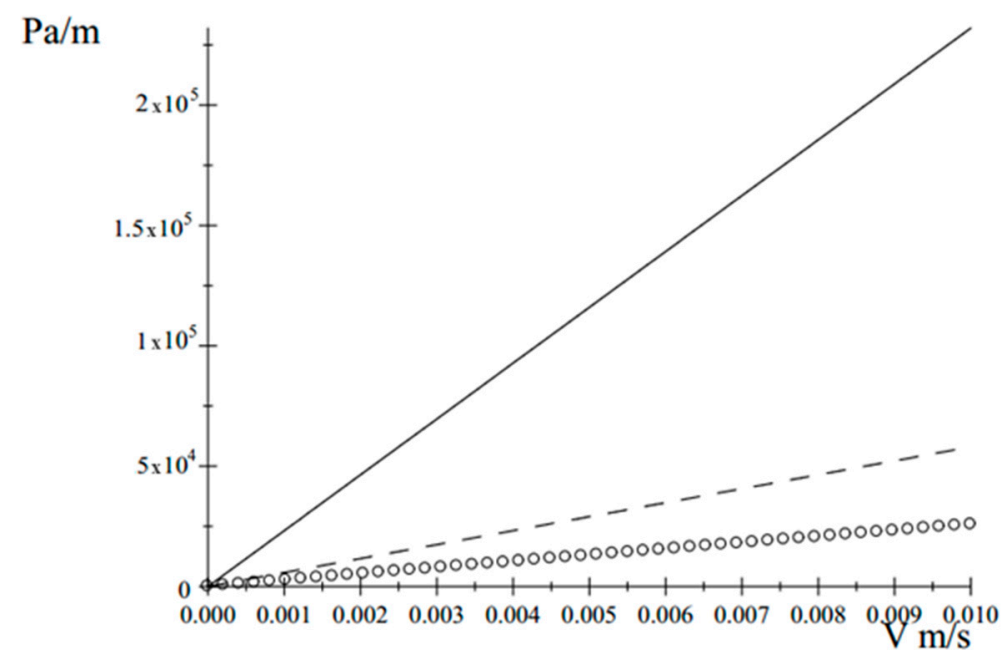

Figure 6. Particle size effect with $\varepsilon=0.4, d_{p}=0.1 \mathrm{~m}$, and $\phi=0.01$ (solid line), 0.02 (dashed line), 0.03 (dotted line).

Figure 7 shows the effect of the bed porosity $(\varepsilon)$ on the pressure gradient, where it is predicted that an increase in porosity decreases the pressure gradient for the same velocity profile.

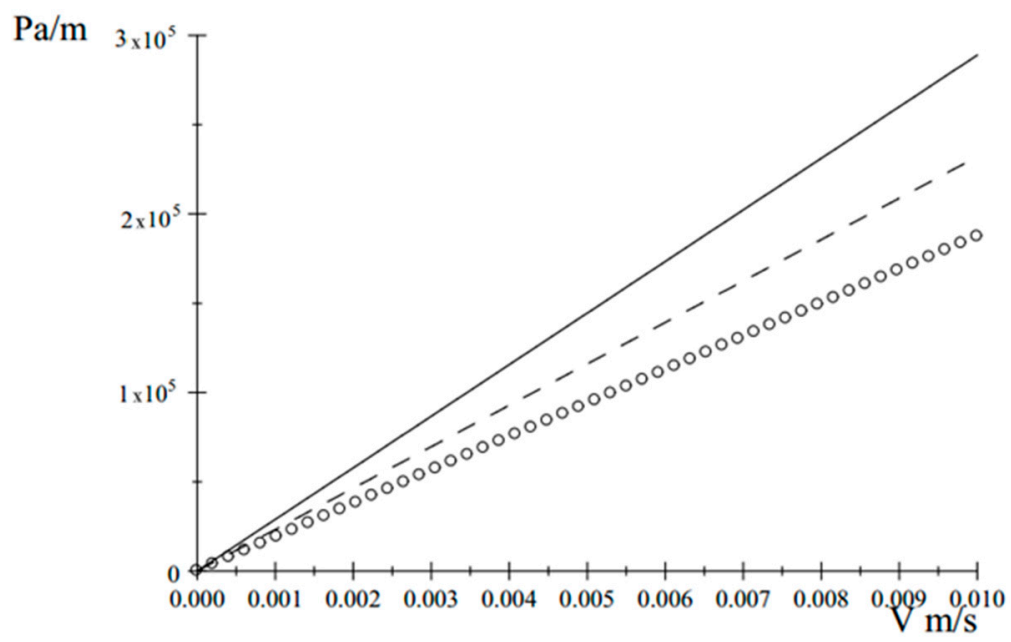

Figure 7. Bed porosity effect with $d_{p}=0.01 \mathrm{~m}, \phi=0.1$, and $\varepsilon=0.38$ (solid line), 0.4 (dashed line), 0.42 (dotted line).

Finally, Figure 8 shows the effect of the phase separation on the pressure gradient, where it is predicted that the use of a demulsifying agent entails a significant decrease in the pressure gradient for a specified velocity. 


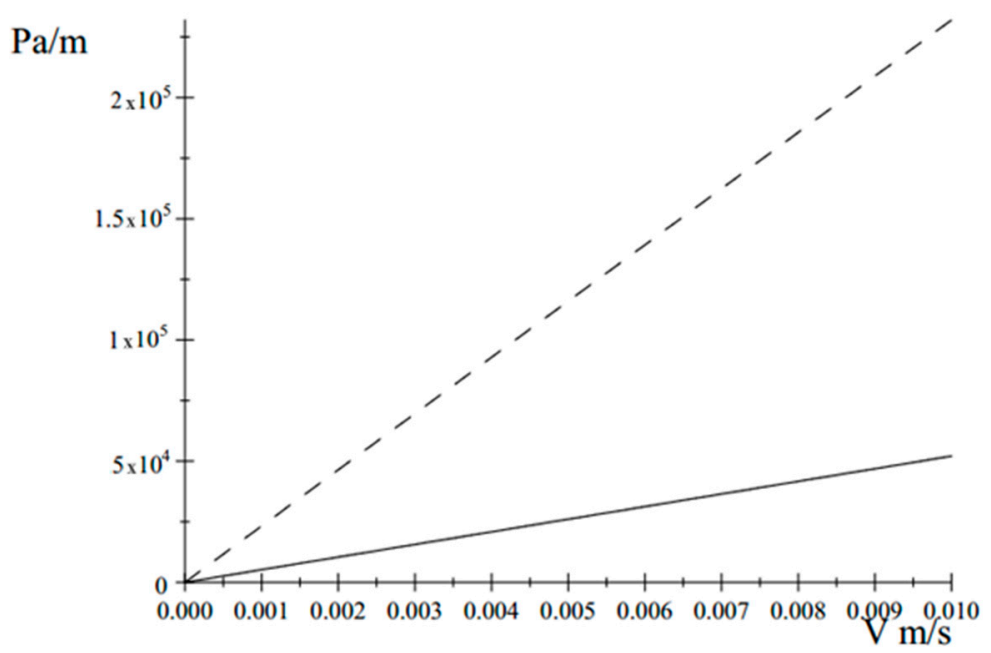

Figure 8. Phase stratification effect. Emulsion (dashed line) and phase separation (solid line) with $d_{p}=$ $0.01 \mathrm{~m}, \phi=0.1$, and $\varepsilon=0.4$.

\section{Conclusions}

This paper presents the preliminary analysis of the surfactant action of four model molecules on W/O emulsions through the determination of the molecular interactions using the $\mathrm{MMH}$ methodology for a paraffin-asphaltene-water surfactant. It was found that the minimum interaction energies that determine the main molecular associations can be taken as the activation energies involved in the study of the behavior of the pressure drop when a dispersed system (e.g., W/O emulsions) flows through porous media.

A mathematical model was developed for the prediction of pressure drop losses for different properties of the system: pore size, particle size, dispersed phase fraction in the fluid, and stratified fluid. From this study, the following aspects are concluded:

1. The model predicts that for an emulsion flowing through a porous bed, the pressure gradient increases with the volume fraction of the dispersed phase, even when the dispersed phase corresponds to a less viscous fluid (which is the expected behavior for these kinds of systems).

2. The pressure gradient increases when the bed porosity increases, and the particle size decreases.

3. If the dispersed phase is less viscous, the destruction of the dispersed system by injecting a demulsifier causes a stratification of the flow that decreases the cut tension in the solid surface, significantly reducing the pressure gradient.

4. The results of the study of the molecular interactions applied to the Eyring viscosity model determined that surfactant molecules $\mathrm{B}$ and $\mathrm{C}$ are suitable for the application of the destabilization of $\mathrm{W} / \mathrm{O}$ emulsions.

From these theoretical approaches, future work is going to exhibit complete crude oil characterization, W/O emulsion properties, and the synthesis and characterization of these surfactants along with the experimental data for the discussion of the semiempirical molecular interactions found. Future work will also present a mathematical model for the prediction of the pressure drop for fluids through porous media in which the effect of the surfactant on W/O emulsions is directly outlined.

Author Contributions: Conceptualization, N.P.D.Z. and E.J.S.D.; Methodology, J.F.P.S.; Software, S.G.S.; Validation, E.F.I.K.; Formal Analysis, J.F.P.S. and E.F.I.K.; Investigation, J.F.P.S., N.P.D.Z. and E.J.S.D.; Resources, N.P.D.Z. and E.J.S.D.; Data Curation, J.F.P.S., E.F.I.K. and S.G.S.; Writing-Original Draft Preparation, J.F.P.S., E.F.I.K. and S.G.S.; Writing-Review \& Editing, N.P.D.Z. and E.J.S.D.; Visualization, J.F.P.S.; Supervision, N.P.D.Z. and E.J.S.D.; Project Administration, N.P.D.Z. and E.J.S.D.; Funding Acquisition, N.P.D.Z. and E.J.S.D.

Funding: This research was funded by CONACYT National Postgraduate Students Scholarship number 470406, CONACYT-Infraestructura grant number 295494, CONACYT-SENER-Hidrocarburos grant number 282278 and PRODEP Support for NPTC (new full-time professors). 
Acknowledgments: Josue F. Perez-Sanchez acknowledges CONACYT for the National Postgraduate Students Scholarship, the National Laboratory of Information Technologies (LaNTI) for the hardware provided and M. Sc. Apolinar Ramírez for his assistance. Nancy P. Diaz-Zavala acknowledges CONACYT for the support under the Infrastructure program 2018-1. Edgardo J. Suarez-Dominguez acknowledges the PRODEP-NPCT program and CONACYT-SENER-Hidrocarburos support.

Conflicts of Interest: The authors declare no conflict of interest.

\section{References}

1. Padula, L.; Balestrin, L.B.D.S.; Rocha, N.D.O.; de Carvalho, C.H.M.; Westfahl, H., Jr.; Cardoso, M.B.; Loh, W. Role of Asphaltenes and Additives on the Viscosity and Microscopic Structure of Heavy Crude Oils. Energy Fuels 2016, 30, 3644-3651. [CrossRef]

2. Lin, Y.-J.; Cao, T.; Chacón-Patiño, M.L.; Rowland, S.M.; Rodgers, R.P.; Yen, A.; Biswal, S.L. Microfluidic Study of the Deposition Dynamics of Asphaltene Subfractions Enriched with Island and Archipelago Motifs. Energy Fuels 2019, 33, 1882-1891. [CrossRef]

3. Giraldo-Dávila, D.; Chacón-Patiño, M.L.; McKenna, A.M.; Blanco-Tirado, C.; Combariza, M.Y. Correlations between Molecular Composition and Adsorption, Aggregation, and Emulsifying Behaviors of PetroPhase 2017 Asphaltenes and Their Thin-Layer Chromatography Fractions. Energy Fuels 2017, 32, 2769-2780. [CrossRef]

4. Moreno-Arciniegas, L.; Babadagli, T. Optimal Application Conditions of Solvent Injection into Oil Sands to Minimize the Effect of Asphaltene Deposition: An Experimental Investigation. SPE Reserv. Evaluation Eng. 2014, 17, 530-546. [CrossRef]

5. Taborda, E.A.; Franco, C.A.; Ruiz, M.A.; Alvarado, V.; Cortés, F.B.; Alvaradov, V. Experimental and Theoretical Study of Viscosity Reduction in Heavy Crude Oils by Addition of Nanoparticles. Energy Fuels 2017, 31, 1329-1338. [CrossRef]

6. Subramanian, D.; Firoozabadi, A. Effect of Surfactants and Water on Inhibition of Asphaltene Precipitation and Deposition. In Abu Dhabi International Petroleum Exhibition and Conference. Soc. Pet. Eng. 2015. [CrossRef]

7. Marcano, F.; Moura, L.G.M.; Cardoso, F.M.R.; Rosa, P.T.V. Evaluation of the Chemical Additive Effect on Asphaltene Aggregation in Dead Oils: A Comparative Study between Ultraviolet-Visible and Near-Infrared-Laser Light Scattering Techniques. Energy Fuels 2015, 29, 2813-2822. [CrossRef]

8. Subramanian, D.; Wu, K.; Firoozabadi, A. Ionic liquids as viscosity modifiers for heavy and extra-heavy crude oils. Fuel 2015, 143, 519-526. [CrossRef]

9. Hashemi, R.; Nassar, N.N.; Almao, P.P. Nanoparticle technology for heavy oil in-situ upgrading and recovery enhancement: Opportunities and challenges. Appl. Energy 2014, 133, 374-387. [CrossRef]

10. Yu, L.; Dong, M.; Ding, B.; Yuan, Y. Emulsification of heavy crude oil in brine and its plugging performance in porous media. Chem. Eng. Sci. 2018, 178, 335-347. [CrossRef]

11. Mandal, A.; Bera, A. Modeling of the flow of oil-in-water emulsions through porous media. Pet. Sci. 2015, 12, 273-281. [CrossRef]

12. Cheng, S.; Fu, M.; Kulacki, F. Characterization of a porous transducer using a capillary bundle model: Permeability and streaming potential prediction. Int. J. Heat Mass Transf. 2018, 118, 349-354. [CrossRef]

13. Suarez-Dominguez, E.J.; Perez-Sanchez, J.F.; Palacio-Perez, A.; Izquierdo-Kulich, E. New mixing rule for the analysis of the influence of a formulation on extra-heavy crude oil viscosity. Rev. Mex. Ing. Quim. 2018, 17, 99-106.

14. Hemmati-Sarapardeh, A.; Aminshahidy, B.; Pajouhandeh, A.; Yousefi, S.H.; Hosseini-Kaldozakh, S.A. A soft computing approach for the determination of crude oil viscosity: Light and intermediate crude oil systems. J. Taiwan Inst. Chem. Eng. 2016, 59, 1-10. [CrossRef]

15. Vesovic, V.; Wakeham, W.A. Transport properties of supercritical fluids and fluids mixtures. In Supercritical Fluid Technology: Reviews in Modern Theory and Applications; Bruno, T.J., Ely, J.F., Eds.; CRC Press: Boca Raton, FL, USA, 2017.

16. Kistemaker, J.C.M.; Lubbe, A.S.; Bloemsma, E.A.; Feringa, B.L. On the Role of Viscosity in the Eyring Equation. ChemPhysChem 2016, 17, 1819-1822. [CrossRef]

17. Langevin, D.; Argillier, J.-F. Interfacial behavior of asphaltenes. Adv. Colloid Interface Sci. 2016, $233,83-93$. [CrossRef] [PubMed] 
18. Montero, L.A.; Molina, J.; Fabian, J. Multiple minima hypersurfaces of water clusters for calculations of association energy. Int. J. Quantum Chem. 2000, 79, 8-16. [CrossRef]

19. Ardèvol, A. Métodos de simulación $\mathrm{QM} / \mathrm{MM}$ y de mecánica estadística: Una aproximación teórica a la biología molecular. Anales de Química 2013, 109, 4.

20. Suarez-Dominguez, E.J.; Xu, B.; Perez-Sanchez, J.F.; Palacio-Perez, A.; Izquierdo-Kulich, E. Stochastic modeling of asphaltenes deposition and prediction of its influence on friction pressure drop. Pet. Sci. Technol. 2018, 36, 1812-1819. [CrossRef]

21. Suárez-Domínguez, E.J.; Pérez-Sánchez, J.F.; Palacio-Pérez, A.; Rodríguez-Valdes, A.; Izquierdo-Kulich, E.; González-Santana, S. A viscosity bio-reducer for extra-heavy crude oil. Pet. Sci. Technol. 2018, 36, 166-172. [CrossRef]

22. Lim, J.S.; Wong, S.F.; Law, M.C.; Samyudia, Y.; Dol, S.S. A review of the effects of emulsions on flow behaviors and common factors affecting the stability of emulsions. J. Appl. Sci. 2015, 15, 167-172.

23. Kolotova, D.S.; Kuchina, Y.A.; Petrova, L.A.; Voron'Ko, N.G.; Derkach, S.R. Rheology of Water-in-Crude Oil Emulsions: Influence of Concentration and Temperature. Colloids Interfaces 2018, 2, 64. [CrossRef]

24. Wong, S.; Lim, J.; Dol, S. Crude oil emulsion: A review on formation, classification and stability of water-in-oil emulsions. J. Pet. Sci. Eng. 2015, 135, 498-504. [CrossRef]

25. Pérez-Sánchez, J.F.; Alarcón-Montelongo, I.S.; Díaz-Zavala, N.P.; Palacio-Pérez, A.; Uárez-Domínguez, E.J. Effect of a viscosity bio-reducer in crude oil performance by Nuclear Magnetic Resonance spectroscopy. Glob. J. Eng. Sci. Res. Manag. 2017, 4, 74-81.

26. Perez-Sanchez, J.F.; Gallegos-Villella, R.R.; Gomez-Espinoza, J.; Suarez-Dominguez, E.J. Determining the effect of a viscosity reducer on water-heavy crude oil emulsions. Int. J. Eng. Adv. Technol. 2019, 8, 844-848.

27. Sosa-Sevilla, J.E.; Perez-Sanchez, J.F.; Melo-Banda, J.A.; Lozano-Navarro, J.I.; Rivera-Armenta, J.L.; Vazquez-Almaguer, A.M.; Diaz-Zavala, N.P. Alcoxybenzoate derivatives and its gelation effect. Pet. Sci. Technol. 2019. [CrossRef]

28. Shi, S.; Wang, Y.; Liu, Y.; Wang, L. A new method for calculating the viscosity of W/O and O/W emulsion. J. Pet. Sci. Eng. 2018, 171, 928-937. [CrossRef]

(C) 2019 by the authors. Licensee MDPI, Basel, Switzerland. This article is an open access article distributed under the terms and conditions of the Creative Commons Attribution (CC BY) license (http://creativecommons.org/licenses/by/4.0/). 